NBER WORKING PAPER SERIES

UNCONDITIONAL CONVERGENCE

Dani Rodrik

Working Paper 17546

http://www.nber.org/papers/w17546

\author{
NATIONAL BUREAU OF ECONOMIC RESEARCH \\ 1050 Massachusetts Avenue \\ Cambridge, MA 02138 \\ October 2011
}

I am grateful to UNIDO for making the INDSTAT4 data base available. I also thank Cynthia Balloch for research assistance, the Weatherhead Center for International Affairs and the Center for International Development at Harvard for financial assistance, and Daron Acemoglu and Jonathan Temple for very useful suggestions. The views expressed herein are those of the author and do not necessarily reflect the views of the National Bureau of Economic Research.

NBER working papers are circulated for discussion and comment purposes. They have not been peerreviewed or been subject to the review by the NBER Board of Directors that accompanies official NBER publications.

(C) 2011 by Dani Rodrik. All rights reserved. Short sections of text, not to exceed two paragraphs, may be quoted without explicit permission provided that full credit, including $\odot$ notice, is given to the source. 
Unconditional Convergence

Dani Rodrik

NBER Working Paper No. 17546

October 2011

JEL No. O1,O4

\begin{abstract}
$\underline{\text { ABSTRACT }}$
Unlike economies as a whole, manufacturing industries exhibit unconditional convergence in labor productivity. The paper documents this finding for 4-digit manufacturing sectors for a large group of developed and developing countries over the period since 1990. The coefficient of unconditional convergence is estimated quite precisely and is large, at 3.0-5.6 percent per year depending on the estimation horizon. The result is robust to a large number of specification tests, and statistically highly significant. Because of data coverage, these findings should be as viewed as applying to the organized, formal parts of manufacturing.
\end{abstract}

Dani Rodrik

John F. Kennedy School of Government

Harvard University

79 JFK Street

Cambridge, MA 02138

and NBER

dani_rodrik@harvard.edu 


\section{UNCONDITIONAL CONVERGENCE}

\section{$\underline{\text { I. Introduction }}$}

Neoclassical growth theory establishes a presumption that countries with access to identical technologies should converge to a common income level. Countries that are poorer and have higher marginal productivity of capital should therefore grow faster in the transition to the long-run steady state. However, empirical work has not been very kind to this proposition. There is no tendency for poor countries to grow faster than rich ones, over any reasonably long time horizon for which we have data (see Figure 1). ${ }^{1}$ Whatever convergence one can find is conditional: it depends on policies, institutions, and other country-specific circumstances. The only exceptions to the rule seem to be states/regions within a unified economy such as the United States (Barro and Sala-i-Martin, 1991). ${ }^{2}$

If growth rates are characterized by conditional instead of unconditional convergence, economies will tend towards different levels of income in the long-run. Lack of empirical support for (unconditional) convergence has led theory in the direction of models with endogenous technological change, which don't necessarily exhibit convergence, and to empirical work that focuses on identifying the conditioning variables that makes convergence feasible (see Acemoglu [2009] on theory and Durlauf, Johnson, and Temple [2005] on empirical work).

In contrast to this large literature, I show in this paper that unconditional convergence does exist, but that it occurs in the modern parts of the economy rather than the economy as a whole. In particular, I document a highly robust tendency towards convergence in labor productivity in manufacturing activities, regardless of geographic location and country-level

\footnotetext{
${ }^{1}$ There exist shorter periods of time over which convergence has been observed. The decade before the global financial crisis of 2008-2009 is one such period (see Subramanian 2011, chap. 4, and Rodrik 2011).

${ }^{2}$ Some studies also find unconditional convergence among the richer OECD countries, but it is difficult to know what to make of this result in light of the obvious sample-selection bias (Baumol 1986; DeLong 1988).
} 
influences. The coefficient of unconditional convergence is estimated quite precisely and is large, at 3.0-5.6 percent per year depending on the estimation horizon. These estimates imply that industries that are, say, a quarter of the way to the technology frontier will experience labor productivity growth at a rate of 4.1-7.8 percentage points per annum. I note that my data come from UNIDO's industrial statistics data base, which is derived largely from industrial surveys. Since microenterprises and informal firms are often excluded from such surveys, my results on unconditional convergence should be as viewed as applying to the organized, formal parts of manufacturing.

The central result of this paper is illustrated in Figure 2. The scatter plot shows the partial relationship between the growth of labor productivity and its initial level controlling for a number of fixed effects. Each dot on the scatter plot represents a 4-digit industry in a specific country. (Illustrative industries: macaroni, noodles \& similar products, pesticides and other agrochemical products, agricultural and forestry machinery.) The two panels depict growth rates over a decade (left-hand side) and five years (right-hand side), respectively. Each country is represented over a single time horizon, with the most recent ten- or five-year period since 1990 for which it has data. Industry, decade, and industry $\times$ decade dummies are included in the regressions used to generate both plots.

Since these plots do not control for country-level determinants, they represent a test of unconditional convergence. (The need for period and industry fixed effects will be motivated subsequently.) The negative and highly significant slope is unmistakable, illustrating the central conclusion of this paper: manufacturing exhibits a strong tendency for unconditional convergence. Industries that start at lower levels of labor productivity experience more rapid growth in labor productivity. As I will show below, when controls for country-specific 
determinant such as policies or institutions are included convergence is even more rapid. But what is striking in Figure 2 is the evident strength of convergence in the data even in the absence of such controls. ${ }^{3}$

To my knowledge, this is the first paper to demonstrate unconditional convergence in industry for a wide range of countries and for detailed manufacturing industries. There does not seem to be any work that has looked at highly disaggregated data for manufacturing or at the manufacturing experience of countries beyond OECD and U.S. states (Bernard and Jones, 1996a and 1996b; see also Sørensen 2001). However, one related study deserves mention. In unpublished work, Hwang (2007, chap. 3) has documented that there is a tendency for unconditional convergence in export unit values in highly disaggregated product lines. Once a country begins to export something, it travels up the value chain in that product regardless of domestic policies or institutions. ${ }^{4}$ Hwang shows that the lower the average unit values of a country's manufactured exports, the faster the country's subsequent growth, unconditionally. This paper differs from Hwang in that it focuses on output rather than exports, and directly on productivity (rather than unit values). Convergence seems to kick in manufacturing regardless of whether production is exported. ${ }^{5}$

Unconditional convergence seems to characterize the vast majority of the (formal) manufacturing industries included in my data. But the estimated convergence coefficient is not uniform. Convergence appears to be least rapid in textiles and clothing and most rapid in

\footnotetext{
${ }^{3}$ It should be clear that my focus in this paper is on what it is typically called "beta-convergence," not "sigmaconvergence." Even if beta-convergence holds, countries may fail to converge in real data as long as random shocks to the growth process are large and act in offsetting manner.

${ }^{4}$ Hwang demonstrates his result for both 10-digit U.S. HS import statistics and 4-digit SITC world trade statistics. The first classification contains thousands of separate product lines.

${ }^{5}$ Also related is a paper by Levchenko and Zhang (2011) which estimates model-based relative productivity trends for 19 manufacturing industries from the 1960s through the 2000 and show that there has been steady convergence across countries.
} 
machinery and equipment, with transport equipment and iron, steel and metal products somewhere in between. So there is a hierarchy within manufacturing that accords well with intuition. Even within manufacturing some of the "escalators" move up more quickly than others.

Another result is that the coefficient of convergence appears to be non-linear. The further away from the frontier an industry, the greater its rate of convergence (the larger the betacoefficient). The plots in Figure 2 give a hint of this non-linearity.

I also discuss in the paper how to reconcile unconditional convergence in manufacturing with its absence for economies as a whole. I use a simple decomposition to identify the factors that weaken the forces of convergence as we aggregate up from individual manufacturing industries. The exercise highlights the role of structural factors, in particular the slow (and sometimes perverse) movement of resources across economic activities with different convergence characteristics.

The trouble from a convergence standpoint is that economic activities that are good at absorbing advanced technologies are not necessarily also good at absorbing labor. As a result, too large a fraction of an economy's resources can get stuck in the "wrong" sectors - those that are not on the escalator up. When firms that are part of international production networks or otherwise benefit from globalization employ little labor, the gains remain limited. Even worse, inter-sectoral labor flows can be perverse with the consequence that convergence within the "advanced" sectors is accompanied by divergence on the part of the economy as a whole. I illustrate these outcomes using the experience of specific countries.

The paper proceeds as follows. Section II describes the data and methods used for the estimation. Section III presents the basic results and various robustness checks. Section IV 
considers the conditions under which convergence may fail to aggregate up to the level of the entire economy. Section V provides concluding remarks.

\section{Data and methods}

A. Date source and description. I use data from UNIDO's INDSTAT 4 data base, which provides industrial statistics for a wide range of countries at the ISIC 4-digit level (UNIDO 2011). These statistics cover value added and employment, among others, for up to 127 manufacturing industries per country, allowing me to calculate labor productivity (value added per employee) and its growth at the same level of disaggregation. ${ }^{6}$ The data are fairly complete for recent years but become more spotty the further back one goes. As a practical matter, it is impossible to calculate growth rates for periods that extend before 1990, so I take that year as the starting point for the empirical work.

With 1990 as the starting point, we cannot look for convergence over long periods of time. In what follows, I restrict attention to growth over two types of time horizons: 10-years and 5-years. The regressions that follow in turn take two forms. They are either pure crosssections for a particular time period, say 1995-2005 or 2002-2007. Or they are pooled regressions where I combine the latest 10- or 5-year period (since 1990) for each country with data. The advantage of the pooled approach is that it maximizes the number of countries that can be included. This yields 40 countries in the case of the 10-year regressions, and 72 in the case of the 5-year regressions. The pooled regressions constitute my baseline specification.

\footnotetext{
${ }^{6}$ Some countries use ISIC combination classifications that cover 2-3 ISIC categories. For consistency, duplicate entries under an ISIC combination code were dropped. Also, there are numerous instances of negative and zero values for value added and employment, which were also removed from the data set.
} 
As mentioned in the introduction, UNIDO's data come from industrial surveys whose coverage differs across countries. Data for developed countries refer for the most part to "all establishments." But in developing countries enterprises with fewer than 5 or 10 employees are typically not included. For this reason, the convergence results below should be read as applying to the more formal, organized parts of manufacturing and not to micro-enterprises or informal firms. The appendix provides a summary of data coverage for each country included in the regressions.

An important problem with the data is that INDSTAT4 provides figures for value added in nominal U.S. dollars. What we need is a measure of growth in labor productivity in real terms. However, on the assumption that 4-digit manufacturing industries in different countries experience a common inflation rate (in U.S. dollars), possibly up to a random error term, we can still exploit the variation within industries across countries to estimate the convergence parameter we need. In what follows, I explain my approach in greater detail.

B. Empirical specification. Dividing nominal value added by employment we calculate nominal labor productivity at the 4-digit level, $v_{i j t}$, where $i$ denotes the industry, $j$ the country and $t$ the time period. The rate of growth of labor productivity in real terms, $\hat{y}_{i j t}$, is given in turn by $\hat{y}_{i j t}=\hat{v}_{i j t}-\pi_{i j t}$, where $\pi_{i j t}$ is the increase in the industry-level deflator and a hat over a variable denotes percent changes.

We assume (real) labor productivity growth in each industry is a function both of country-specific conditions and of the convergence potential. The latter in turn is proportional to the gap with each industry's own frontier technology, represented by $y_{i t}^{*}$. Hence:

$$
\hat{y}_{i j t}=\beta\left(\ln y_{i t}^{*}-\ln y_{i j t}\right)+D_{j}
$$


where $D_{j}$ is a dummy variable that stands in for all time- and industry-invariant country-specific factors. The convergence coefficient we are interested in estimating is $\beta$. Note that if $\ln y_{i j t}$ is measured with error, this specification potentially introduces a bias towards over-estimating the rate of convergence, since such an error weakens the link between initial productivity and final productivity. This is a common problem in the empirical literature on convergence (Temple 1998).

The last step is to assume a common global (U.S. dollar) inflation rate for each individual industry, $\pi_{i j t}=\pi_{i t}+\varepsilon_{i j t}$, up to an idiosyncratic (random) error term. This is a reasonable assumption since all the industries in question are manufactures and tradable, facing common world prices. Domestic prices may diverge from world prices due to transport costs, import tariffs or export subsidies, but such wedges introduce differences in levels, not growth rates. Equivalently, we can simply assume that dollar inflation rates are not systematically correlated with an industry's distance from the technological frontier. This allows us to express the growth of nominal labor productivity as follows:

$$
\hat{v}_{i j t}=-\beta\left(\ln y_{i j t}-\ln y_{i t}^{*}\right)+\pi_{i t}+D_{j}+\varepsilon_{i j t} .
$$

We assume $\varepsilon_{i j t}$ is uncorrelated with other explanatory variables and captures all other idiosyncratic influences on measured labor productivity. Re-arranging terms, we now have our final estimating equation:

$$
\hat{v}_{i j t}=-\beta \ln y_{i j t}+\left(\pi_{i t}+\beta \ln y_{i t}^{*}\right)+D_{j}+\varepsilon_{i j t},
$$

This can be expressed equivalently as

$$
\hat{v}_{i j t}=-\beta \ln y_{i j t}+D_{i t}+D_{j}+\varepsilon_{i j t},
$$

where $D_{i t}$ stands for $\left(\pi_{i t}+\beta \ln y_{i t}^{*}\right)$. Hence we can regress the growth of labor productivity in U.S. dollar terms on the initial level of labor productivity, a set of industry $\times$ time period fixed 
effects $\left(D_{i t}\right)$ and country fixed effects $\left(D_{j}\right)$. In the specifications below, I will include separate industry and period dummies as well for completeness.

It is also possible to run this regression over a single time period, as a pure cross-section. In this case, the industry $\times$ time period fixed effects are reduced to industry fixed effects:

$$
\hat{v}_{i j}=-\beta \ln y_{i j}+D_{i}+D_{j}+\varepsilon_{i j} .
$$

As specified, our estimate of $\beta$ will be a measure of conditional convergence, since country-specific conditions are explicitly controlled for by the country fixed effects. A test of unconditional convergence consists of dropping these country dummies and checking whether the estimated coefficient $-\beta$ remains negative and statistically significant.

\section{Empirical results}

A. Basic results. Tables 1 and 2 show results for the 10- and 5-year growth regressions, respectively. The dependent variables in each case are the (compound annual) growth rates of labor productivity for 4-digit manufacturing industries. The regressors are the log of initial labor productivity and a host of fixed effects, depending on the specification. The regressions for each time period are run first without and then with country dummies. As explained previously, these two specifications yield the unconditional and conditional convergence coefficients, respectively. The tables display results for the pooled sample first, followed by cross-sections covering specific time periods. (The first columns of the pooled specifications correspond to the scatter plots displayed in Figure 2). Standard errors are clustered at the country level in all specifications.

The estimated unconditional convergence coefficient is highly significant in almost all specifications. The only exceptions are the two earliest samples, which cover very few countries 
(1991-2001 with 12 countries and 1990-2000 with 7 countries). The coefficient estimate ranges from -1.6 percent (1992-2002) to -9.0 percent (2002-2007). The estimates from the baseline (pooled) specifications are -3.0 and -5.6 percent, for the 10- and 5-year regressions respectively. The more recent samples generally tend to yield higher estimates, as do the 5-year regressions (compared to the 10-year specifications). Since the country coverage varies across these different time periods and specifications, it is not possible to directly compare these results or ascertain why they differ. However, the convergence coefficient is generally higher (in absolute value) when the sample contains a larger number of lower-income economies (as the larger and more recent samples tend to do). This seems to be related to a non-linearity in income, as I will show below.

Each specification in Tables 1 and 2 is paired with its conditional variant, including country fixed effects. The estimated convergence coefficients always increase in size, typically doubling when country dummies are included. This is as expected in view of the conditional convergence results in the literature. Country-specific conditions obviously play a role in determining the speed of catch-up. What is surprising is how systematic and apparently rapid productivity convergence in individual manufacturing industries is even when country-specific conditions are not taken into account.

Since the data I work with are post-1990, one question is whether there is something special about this more recent period. It could be that globalization and the spread of global production networks now greatly facilitate technological dissemination and therefore catch-up. We cannot rule out the possibility that manufacturing industries were not subject to unconditional convergence in earlier periods. But what we can rule out is that aggregate productivity also exhibits unconditional convergence since 1990. As Figure 3 shows, economy- 
wide labor productivity (GDP per worker) shows no tendency towards convergence during the time period under analysis. This is true for the most comprehensive sample of countries, as well as for the samples where the country coverage is restricted to the countries included in my industry regressions (both the 10-year and 5-year regressions, separately).

B. $\quad$ Robustness. Table 3 presents a number of additional robustness tests. I take the pooled specification from Table 1 as my baseline and re-run the same specification with the following changes: (i) using a 3-digit disaggregation for manufacturing industries (instead of 4-digit); (ii) re-calculating growth rates by estimating a log-linear trend using all 10 annual observations instead of end-points only; ${ }^{7}$ (iii) excluding observations that correspond to the highest and lowest 10 percent values for growth; (iv) excluding countries that enter with fewer than 40 industries; (v) excluding observations in the top and bottom, respectively, of the sample in terms of labor productivity; (vi) excluding former socialist countries (whose unusual experience during the 1990s may need special care in interpretation) from the sample; (vii) running weighted regressions with (log) value added as weights.

Encouragingly, the estimated convergence coefficient remains statistically highly significant in all these variants. Note in particular that the estimated coefficient remains unchanged when we weight industries by size. ${ }^{8}$ Hence the convergence result is not driven by the experience of relatively small industries. The main changes of note in Table 3 are the following. First, when the top and bottom $10 \%$ of growth observations are removed from the sample, the point estimate of the convergence coefficient is reduced to -1.3 percent (column 4), but remains highly significant. Second, the convergence coefficient for the bottom half of the

\footnotetext{
${ }^{7}$ This guards against introducing a spurious bias that may arise from lagged labor productivity appearing directly on both sides of the regression equation, with opposite signs.

${ }^{8}$ Using employment weights produces nearly identical results.
} 
labor-productivity sample is decidedly larger than that for the top half (columns 6 and 7), indicating once again a degree of non-linearity.

Another type of robustness check is to scrutinize the convergence experience on an industry-by-industry basis. This would be the direct analogue of running cross-country growth regressions, where we regress, separately for each industry, the growth rate of an industry's labor productivity against its initial level across all countries in the sample that have the requisite data:

$$
\hat{\mathrm{v}}_{\mathrm{ij}}=-\beta \ln \mathrm{y}_{\mathrm{ij}}+\varepsilon_{\mathrm{ij}} \quad \text { for } i=1, \ldots, \mathrm{I} .
$$

This entails running as many regressions as we have manufacturing industries. Pooling is no longer appropriate since now we cannot control for industry-specific inflation trends through industry $\times$ period dummies. Taking the $2000-2005$ period to maximize the number of countries (and hence observations), we are able to run 127 individual industry convergence regressions. Most of these regressions cover 30-40 countries, so we should not be too demanding in terms of statistical significance for industry-specific estimates.

Figure 4 summarizes the results by showing the distribution of estimated convergence coefficients across the 127 industries. The vast majority of the estimates are negative, and most lie between 0 and -10 percent. While not all these coefficient estimates are statistically significant, a surprising number of the negative ones are. Specifically, 76 (out of 127) of the industry regressions yield negative and statistically significant convergence coefficients (at the $95 \%$ level or higher). By contrast, none of the (few) positive coefficients are statistically significant. Figure 5 presents scatter plots for four specific industries to give a visual sense of the results.

One possible concern in interpreting these results is that my assumption of a common value added deflator (in dollars) for each 4-digit industry, regardless of the country in which it is 
located, may be introducing a bias to the estimation. I justified this assumption previously by arguing that the manufacturing industries in question are tradable, and hence face common world prices. Domestic trade and subsidy policies may well drive a wedge between domestic and world prices. But as long as these wedges do not change over time in a systematic fashionenabling domestic prices to experience greater inflation in the industries that are the furthest away from the technological frontier - my results should remain unbiased.

A different kind of potential complication arises from systematic changes in real exchange rates. In principle, across-the-board increases in domestic costs such as wages should be offset, on average, by depreciation of the home currency, leaving dollar values generally unchanged. But in countries that experience sustained movements in their real exchange rate, trends in value added expressed in U.S. dollars will be misleading with regard to productivity in individual manufacturing industries. The worst case, from the perspective of the present paper, would be if the low-income countries which house a preponderant share of low-productivity industries were the ones to experience real exchange rate appreciations - a rise in domestic costs not compensated by currency depreciation. This would lead to an upward bias in our convergence estimates.

To check against this possibility, Table 4 provides some additional robustness tests dealing with real exchange rates. I follow two strategies to check for the possibility of the kind of bias identified above. First, I divide the countries into four quartiles, ranked by the percent change in their real exchange rate over the relevant period. ${ }^{9}$ I run the baseline specification separately for each quartile to see if there are appreciable differences in the estimated speed of

\footnotetext{
${ }^{9}$ These are conventional bilateral real exchange rates vis-à-vis the U.S. Domestic inflation rates have been calculated using producer-price indices where possible, substituting the CPI where PPI is not available. The source for the data on exchange rates and price indices is the IMF's International Financial Statistics. A few countries had to be dropped because of lack of price data.
} 
convergence across quartiles. Second, I rescale the growth in value added per worker by deflating these numbers with (one plus) the rate of appreciation of the country's real exchange rate. I rerun the baseline specification using these adjusted values for the dependent variable.

The results shown in Table 4 are comforting. There is some evidence for the 5-year sample that systematic changes in the real exchange rate may have imparted an upward bias to the convergence estimates for that sample. But the rescaled estimate is reduced only marginally (from 0.056 to 0.050 ), and the estimated convergence coefficient remains highly significant even in the group of countries that have experienced the greatest appreciation. The 10-year sample, by contrast, shows little difference across quartiles or between the baseline and rescaled estimates. In all, there is little evidence that real exchange rate movements have distorted our basic findings.

Another source of possible bias arises from compositional changes. Even 4-digit industries are a mix of different activities, and what appears as an increase in dollar values may be in reality a shift towards higher value-added activities within the same industry (Schott 2004; Hwang 2007). It is possible that industries that start further away from the frontier experience such shifts more rapidly. From the present perspective, however, this is of lesser concern. To the extent that such product upgrading takes place generally, it is another manifestation of the productive convergence we are interested in tracking.

Finally, I note that I have re-estimated convergence using growth rates for gross output per employee, rather than for value added per employee. Output per employee may not capture productivity trends accurately when the share of intermediate inputs changes. But since output prices may diverge from value-added deflators and are more closely linked to world market 
prices, this serves as an additional robustness check. These results (not shown) are very similar to those reported above and remain highly significant.

C. Further results. I have already mentioned that the estimated convergence coefficient seems to exhibit non-linearity. This issue is analyzed more systematically in Table 5. The first two columns add the square of productivity to the baseline specification. The quadratic term enters with a positive coefficient that is highly significant. The remaining two columns check for non-linearity by estimating separate convergence coefficients for industries separated into quartiles according to their labor productivity. Industries that are further away from the frontier have larger convergence coefficients. The bottom line is that the rate of convergence is higher in the least productive manufacturing industries.

Next I check whether there are appreciable differences across industries in the speed of convergence. I have grouped 4-digit industries into larger sub-groups, such as textiles and clothing, chemicals, and transport equipment. I find that estimated convergence coefficient is negative and significant for each of these sub-groups. However, there are significant differences in the magnitudes of the coefficients, shown in Table 6, that seem interesting. (The table shows a pared down specification which includes interaction terms with just a few of the sub-groups.) We note that food, beverages, and tobacco and textiles and clothing have the lowest convergence coefficients (in absolute value). These activities tend to be technologically the least sophisticated ones. Put differently, these are activities where the convergence gap in poor countries is relatively modest. On the other hand, the most rapid convergence seems to take place in the machinery and equipment industries. 


\section{Why unconditional convergence may not aggregate up}

The forces of convergence seem quite strong in manufacturing industries. It stands to reason that we would uncover similar results for certain other parts of the economy as well, perhaps modern, tradable services such as financial or business services among others. We might expect convergence at the sectoral level to produce aggregate convergence as well, especially if converging sectors also attract more resources and become larger over time. Yet the aggregate data do not support this conjecture as we have seen. In this section I consider why economies as a whole may fail to exhibit unconditional converge despite the pull of convergence within manufacturing industries.

We shall analyze the conditions under which convergence aggregates up. We begin by expressing aggregate value added per worker in country $j, \mathrm{y}_{\mathrm{j}}$, as a weighted average of labor productivity in each industry:

$$
y_{j}=\sum_{i} \alpha_{i j} y_{i j}
$$

where the weights $\alpha_{i j}$ are the employment share of each industry. Depending on the nature of the exercise, this aggregate may refer to manufacturing as a whole (in which case it would be MVA per worker) or to the entire economy (GDP per worker). Differentiating this expression totally and dividing through by $y_{j}$ we get the proportional growth rate of aggregate productivity:

$$
\hat{y}_{j}=\sum_{i} \alpha_{i j} \theta_{i j} \hat{y}_{i j}+\sum_{i} \theta_{i j} d \alpha_{i j}
$$

where $\theta_{i j}=y_{i j} / y_{j}$ is the productivity of each industry relative to the average. The first term here represents the appropriately weighted average of productivity growth across individual industries, while the second term captures the productivity effects of labor re-allocation across industries. The second term is positive (negative) insofar as relatively more productive sectors increase (decrease) their employment share. 
Let the set of industries characterized by unconditional convergence be denoted by $C$. Productivity in these industries evolves according to the following equation:

$$
\hat{y}_{i j}=\beta_{\mathrm{i}}\left(\ln y_{i}^{*}-\ln y_{i j}\right), \quad \text { for } i \in C .
$$

Note that we allow for differences in convergence behavior across industries (and have dropped the time subscripts). Productivity growth in the non-convergence industries - such as traditional agriculture or informal activities, denoted by $N C$ - is given by $g_{i j}$ for $i \in N C$.

Combining this information with the preceding equation and re-arranging yields:

$$
\begin{aligned}
& \hat{y}_{j}=-\sum_{i \in C} \beta_{i} \alpha_{i j} \theta_{i j} \ln y_{i j} \quad \text { (1) pure convergence } \\
& +\sum_{i \in C} \beta_{i} \alpha_{i j} \theta_{i j} \ln y_{i}^{*} \quad \text { (2) average distance to frontier } \\
& +\sum_{i \in N C} \alpha_{i j} \theta_{i j} g_{i j} \quad \text { (3) production structure effect } \\
& +\sum_{i} \theta_{i j} d \alpha_{i j} \quad \text { (4) re-allocation effect }
\end{aligned}
$$

This equation expresses growth in aggregate labor productivity as the sum of four effects. The first term captures the direct influence of convergence industries. Since $\beta_{i}>0$, countries that are poorer in the sense of having low levels of (appropriately averaged) productivity in convergence industries will tend grow more rapidly, everything else the same. The other three terms, however, can possibly confound this effect in practice. These terms capture the effect of economic structure and its change over time.

First, even within convergence industries, poor economies may specialize (have high $\alpha_{i j}$ ) in those activities where convergence is less rapid and/or the productivity frontier not too far away (term 2). Second, poorer countries may have a greater propensity to specialize in nonconvergence industries (term 3). And third, resources in poorer countries may move over time in 
the "wrong direction" - to industries with low relative productivity (low $\theta_{i j}$ ) (term 4). In all these cases, the forces of convergence will be blunted, and may fail entirely. If structural differences across rich and poor countries are sufficiently pronounced in the ways just described, it is possible for aggregate data to show no convergence, despite positive convergence in individual industries. The key here is that sectoral employment shares may vary systematically with incomes so as to eliminate overall convergence possibilities.

I illustrate the quantitative significance of these structural features with two exercises, one for manufacturing and one for the economy as a whole. For the first exercise, I compute the magnitudes of terms 1 and 2 in the above decomposition for each of the countries in my 40country sample, using actual values in the dataset. I set $\beta_{i}$ equal to 1.5 percent for textiles and clothing, 3.8 percent for machinery and equipment, and 3.1 percent for the rest of manufacturing. I set the values of $y_{i}^{*}$ to the highest level of labor productivity observed in the data. The values of $\alpha_{i j}$ and $\theta_{i j}$ are also calculated from the raw data for each country. The values for terms 1 and 2 that we thus obtain for each country are plotted in Figure 6 against average manufacturing productivity.

The "pure convergence" effect (term 1) is, as predicted, a negatively sloped relationship, indicating that poorer economies get a bigger growth kick out of it. What is of interest in Figure 6 is that what I have called the "distance to frontier" effect (term 2) is positively sloped and hence acts in an offsetting manner. In fact, the correlation coefficient between terms 1 and 2 across countries is very high (-0.85). What this indicates is that the forces of convergence across countries are blunted, even within manufacturing, by prevailing patterns of specialization. Poorer countries have proportionately more labor in manufacturing industries with low rates of convergence or with technological frontiers that are less distant. 
These within-manufacturing effects are often aggravated by broad inter-sectoral shifts. McMillan and Rodrik (2011) show that perverse structural shifts have played a large role in recent decades in depressing productivity growth in Africa and Latin America. My second exercise, taken directly from McMillan and Rodrik (2011), illustrates the importance of term 4 in the decomposition above.

Figure 7 displays a particularly egregious instance of perverse structural change in Argentina. Between 1990 and 2005, manufacturing industries in Argentina lost more than 6 percentage points in terms of employment share. Most of this de-industrialization took place during the 1990s, under the Argentine experiment with hyper-openness. Even though the decline in manufacturing was halted and partially reversed following the devaluation and recovery from the financial crisis of 2001-2002, this was not enough to change the overall picture for the period 1990-2005. The sector experiencing the largest employment gain over this period was community, personal, and government services, which has a high level of informality and is among the least productive in the economy. Hence when we plot the employment gains of individual sectors against their relative productivity we get a sharply negative slope (Figure 7). Computing the aggregate effects as indicated by term 4 , we reach the results that perverse structural change has reduced Argentina's labor productivity growth by 0.6 percentage points per annum, a quarter of the economy's actual productivity growth over this period.

\section{Concluding remarks}

I have provided evidence in this paper that unconditional convergence is alive and well. But one needs to look for it among manufacturing industries rather than entire economies. It is perhaps not surprising that manufacturing industries should exhibit unconditional convergence, 
and if the estimates here are to be believed, at quite a rapid pace too. These industries produce tradable goods and can be rapidly integrated into global production networks, facilitating technology transfer and absorption. Even when they produce just for the home market, they operate under competitive threat from efficient suppliers from abroad, requiring that they upgrade their operations and remain efficient. Traditional agriculture, many non-tradable services, and especially informal economic activities do not share these characteristics.

The findings in this paper offer new insight on the determinants of economic growth and convergence across countries. They suggest that lack of convergence is due not so much to economy-wide misgovernance or endogenous technological change, but to specific circumstances that influence the speed of structural reallocation from non-convergence to convergence activities. The policies that matter are those that bear directly on this reallocation. As discussed in Rodrik (2011), what high-growth countries typically have in common is their ability to deploy policies that compensate for the market and government failures that block growth-enhancing structural transformation. Countries that manage to affect the requisite structural change grow rapidly while those that fail don't. 


\section{REFERENCES}

Acemoglu, Daron, Introduction to Modern Economic Growth, Princeton University Press, Princeton, NJ, 2009.

Barro, Robert, and Xavier Sala-i-Martin, “Convergence across States and Regions,” Brookings Papers on Economic Activity, 1991:1, 107-158.

Baumol, William, "Productivity Growth, Convergence, and Welfare: What the Long-Run Data Show," American Economic Review, 76(5), 1986, 1072-1085.

Bernard, Andrew, and Charles Jones, "Productivity and Convergence across U.S. States and Industries,” Empirical Economics, March 1996, Vol. 21, pp. 113-135. [1996a]

Bernard, Andrew, and Charles Jones, "Comparing Apples to Oranges: Productivity Convergence and Measurement Across Industries and Countries," American Economic Review, December 1996, Vol. 86, pp. 1216-1238. [1996b]

DeLong, J. Bradford, "Productivity Growth, Convergence, and Welfare: Comment," American Economic Review, 78(5), 1988, 1138-1154.

Durlauf, Steven, Paul Johnson, and Jonathan Temple. "Growth Econometrics," in P. Aghion and S. Durlauf, eds., Handbook of Economic Growth, North-Holland, Amsterdam, 2005.

Hwang, Jason J., "Patterns of Specialization and Economic Growth," unpublished Ph.D dissertation, Economics Department, Harvard University, May 2007.

Levchenko, Andrei A., and Jing Zhang, "The Evolution of Comparative Advantage: Measurement and Welfare Implications," Working Paper No. 16806, NBER (http://www.nber.org/papers/w16806), February 2011.

Maddison, Angus, "Historical Statistics of the World Economy: 1-2008 AD," 2010, available at http://www.ggdc.net/maddison/Historical_Statistics/horizontal-file_02-2010.xls.

McMillan, Margaret, and Dani Rodrik, "Globalization, Structural Change, and Productivity Growth,” NBER Working Paper No. 17143, June 2011.

Rodrik, Dani, “The Future of Economic Convergence,” NBER Working Paper No. 17400, September 2011.

Schott, Peter K., "Across-Product versus Within-Product Specialization in International Trade," Quarterly Journal of Economics, 119(2), 2004, 647-678.

Sørensen, Anders, "Comparing Apples and Oranges: Productivity Convergence and Measurement Across Industries and Countries: Comment," American Economic Review, 91(4), September 2001, 1160-1167. 
Subramanian, Arvind, Eclipse: Living in the Shadow of China's Economic Dominance, Peterson Institute for International Economics, Washington, DC, 2011.

Temple, Jonathan R. W., "Robustness Tests of the Augmented Solow Model," Journal of Applied Econometrics, 13(4), 1998, 361-375.

United Nations Industrial Development Organization (UNIDO), "INDSTAT4

Industrial Statistics Database - 2011 edition," 2011

(http://www.unido.org/index.php?id=1000309). 

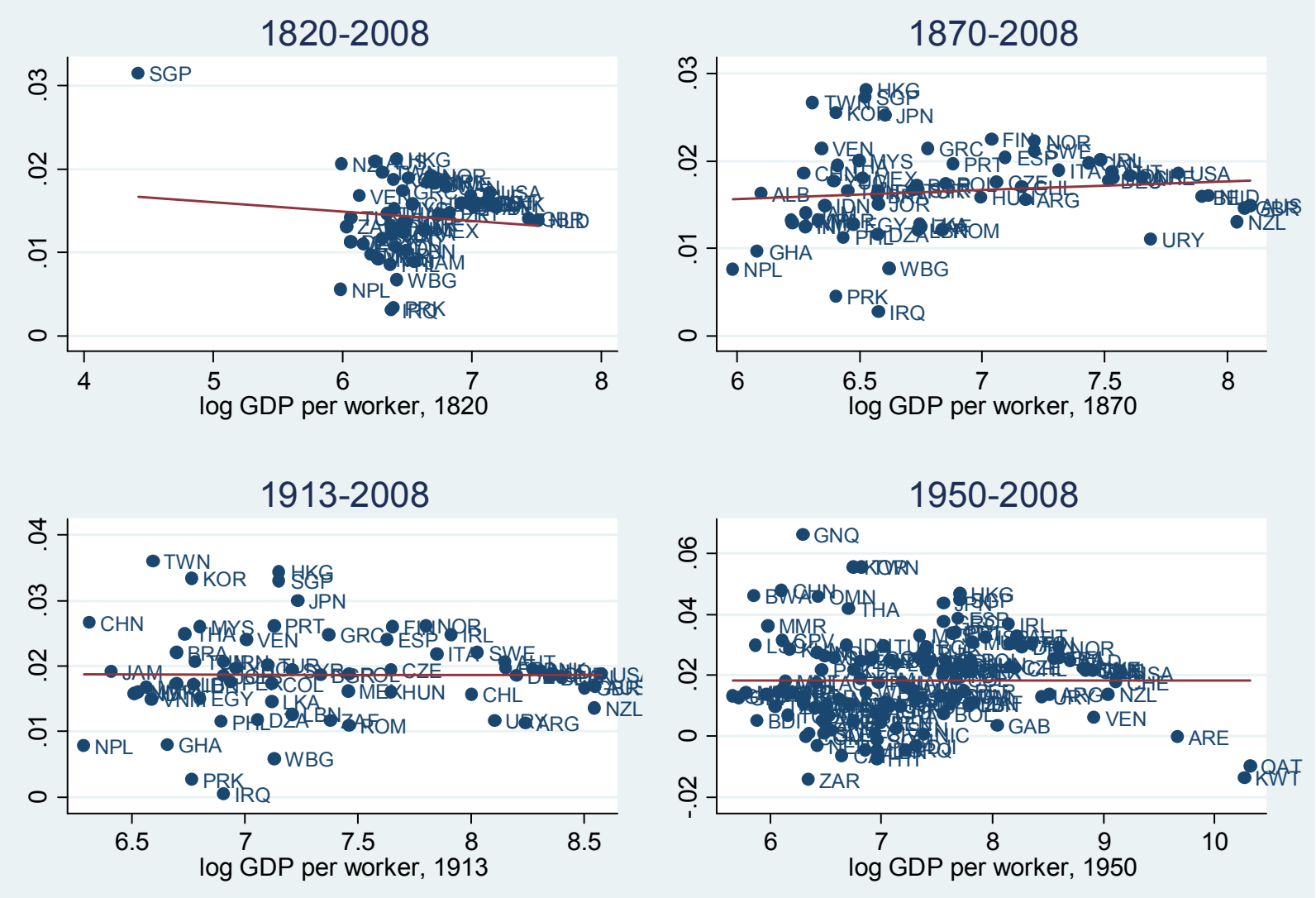

Figure 1: Relationship between growth (vertical axis) and initial income over different time horizons.

Source: Author's computations from Maddison (2010). 

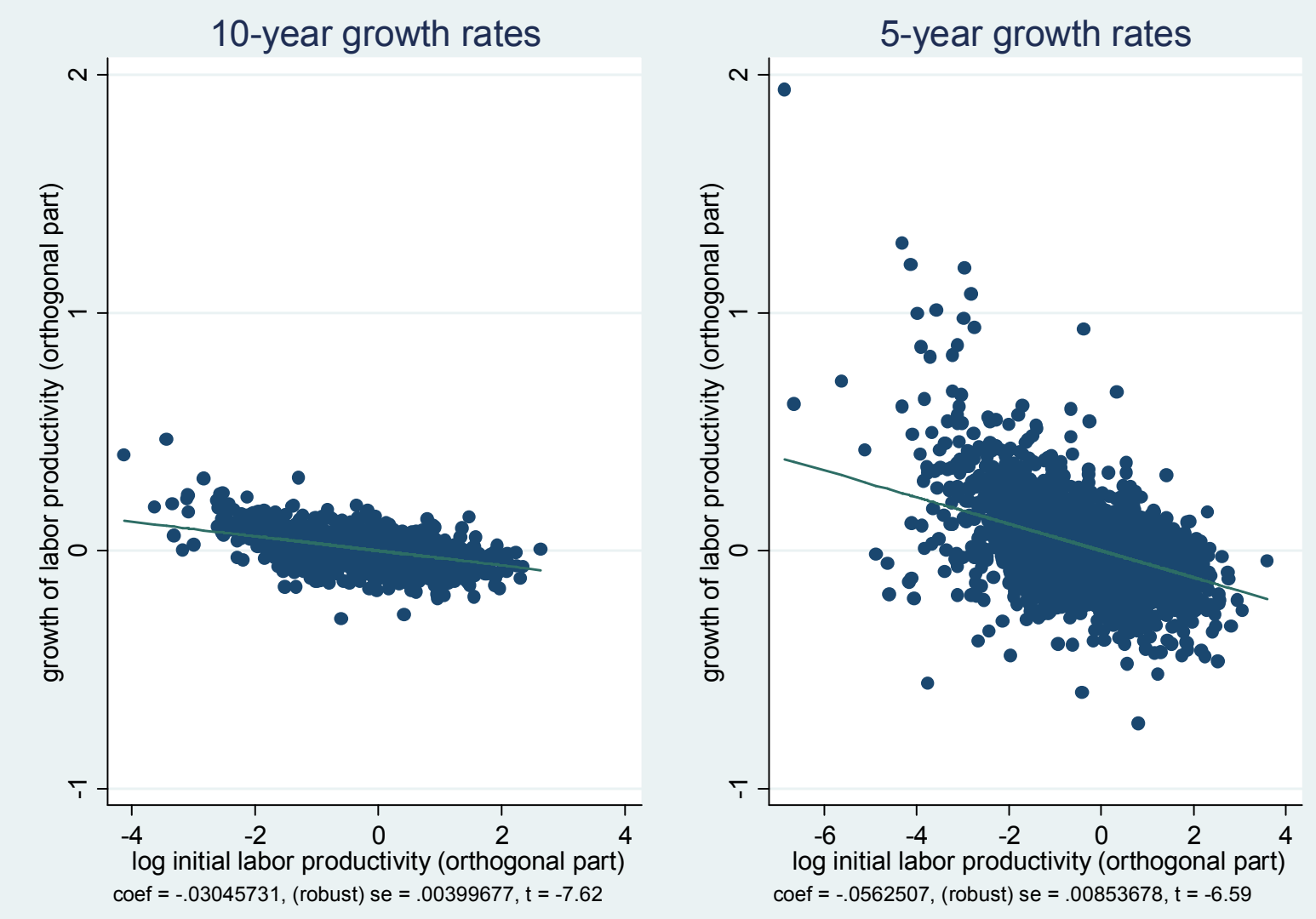

Figure 2: Unconditional convergence in 4-digit industries 

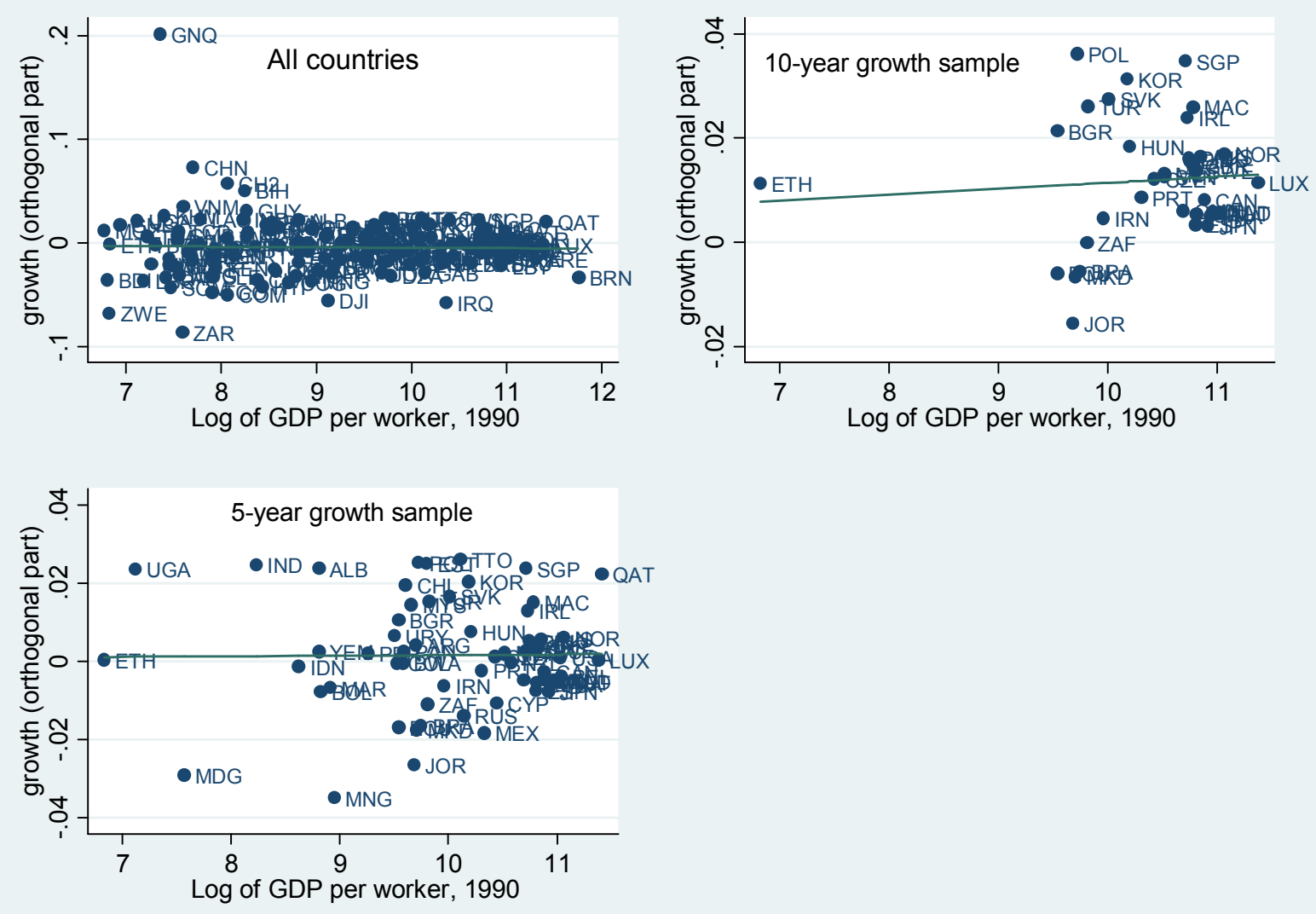

Figure 3: Unconditional convergence at the country level, 1990-2007 


\section{Distribution of betas across industries 2000-2005 growth regressions}

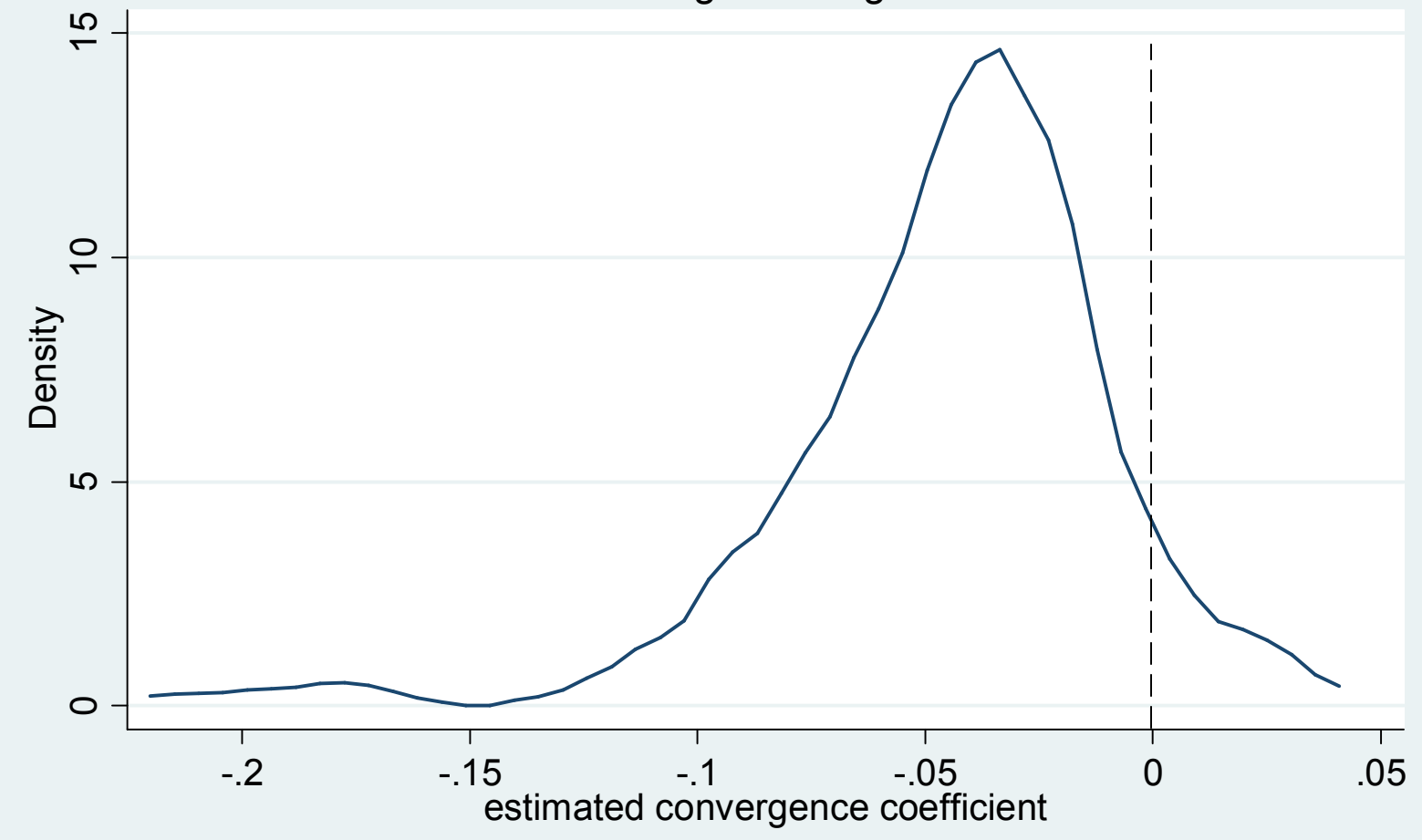

Kernel density estimate; kernel $=$ epanechnikov, bandwidth $=0.0096$

Figure 4: Kernel density estimate of convergence coefficients across 4-digit industries, 2000-2005 
Productivity convergence in individual industries, 2000-2005
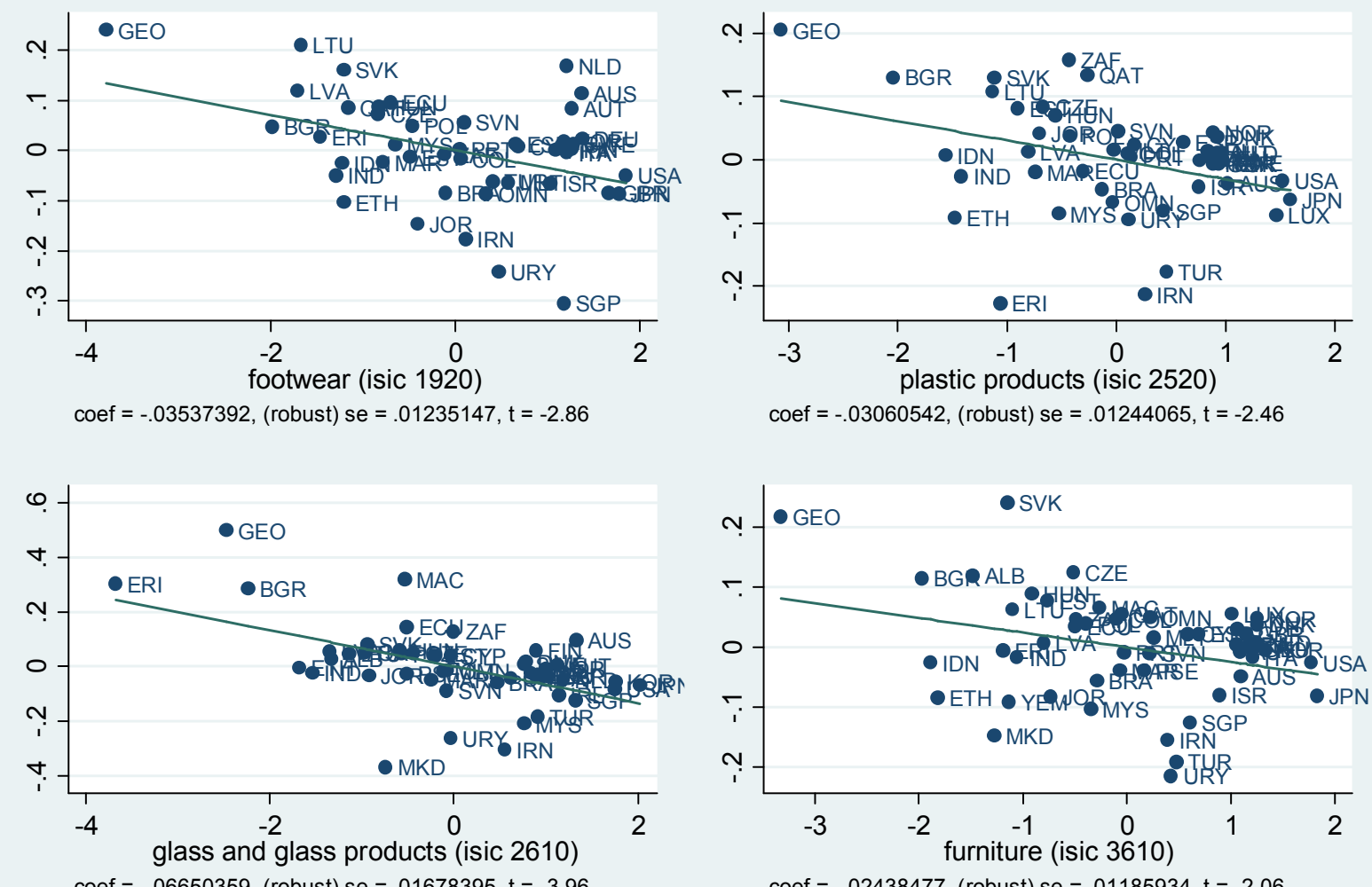

coef $=-.06650359$, (robust) $\mathrm{se}=.01678395, \mathrm{t}=-3.96$

coef $=-.02438477$, (robust) se $=.01185934, t=-2.06$

Figure 5: Convergence in four manufacturing industries 


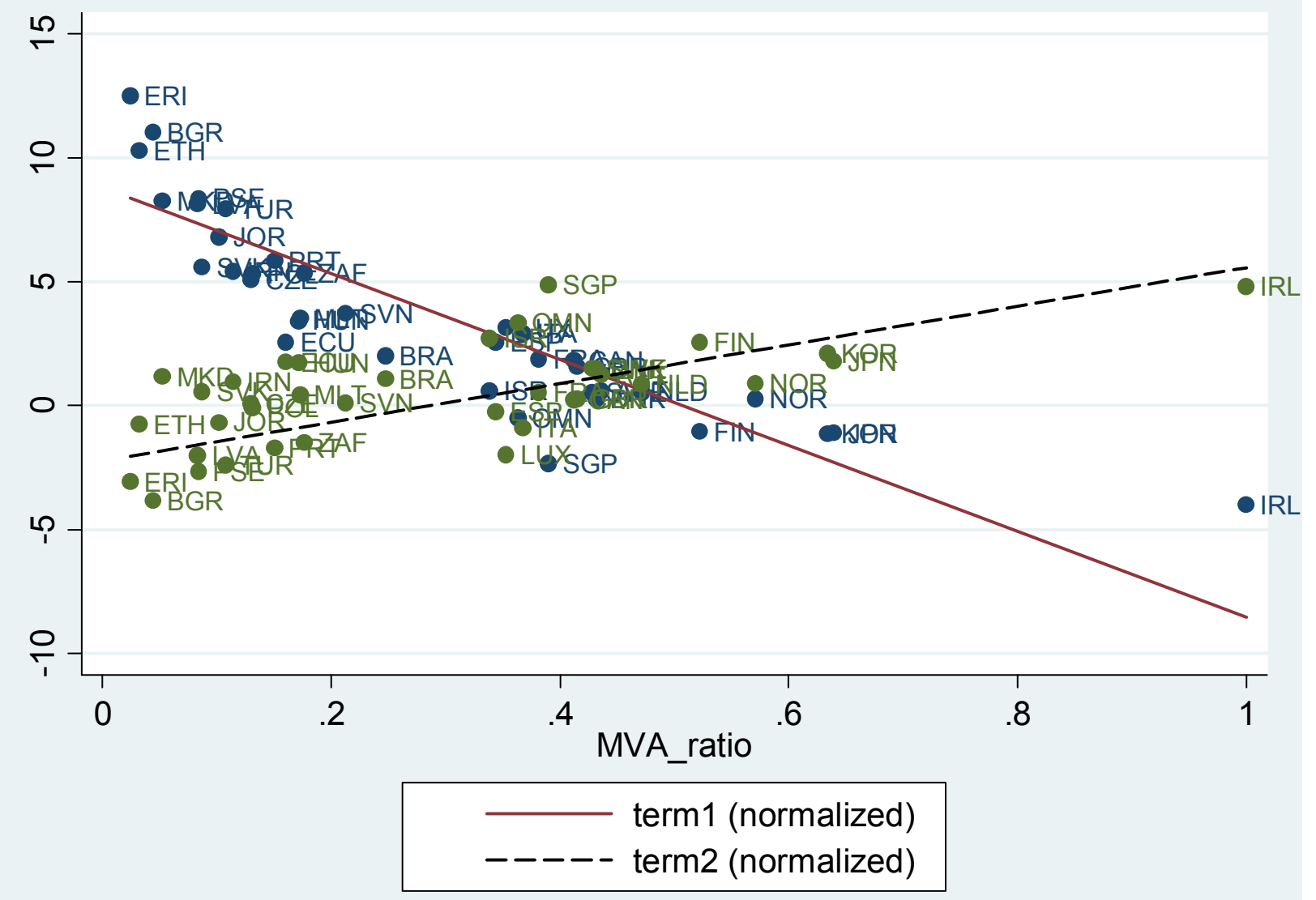

Figure 6: Relationship between "pure convergence" and "distance to frontier" effects at different levels of aggregate productivity 


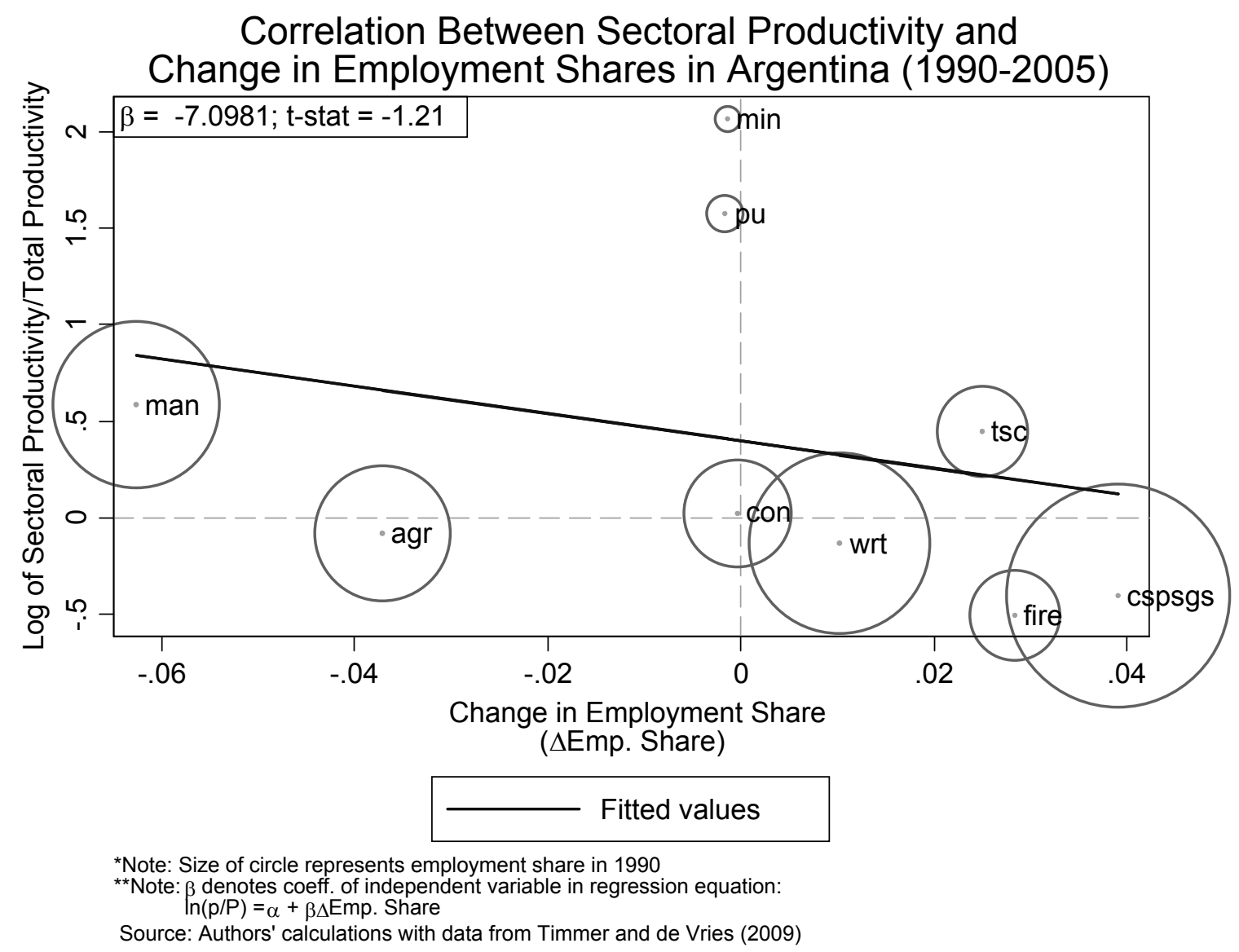

Figure 7: Perverse structural change in Argentina 


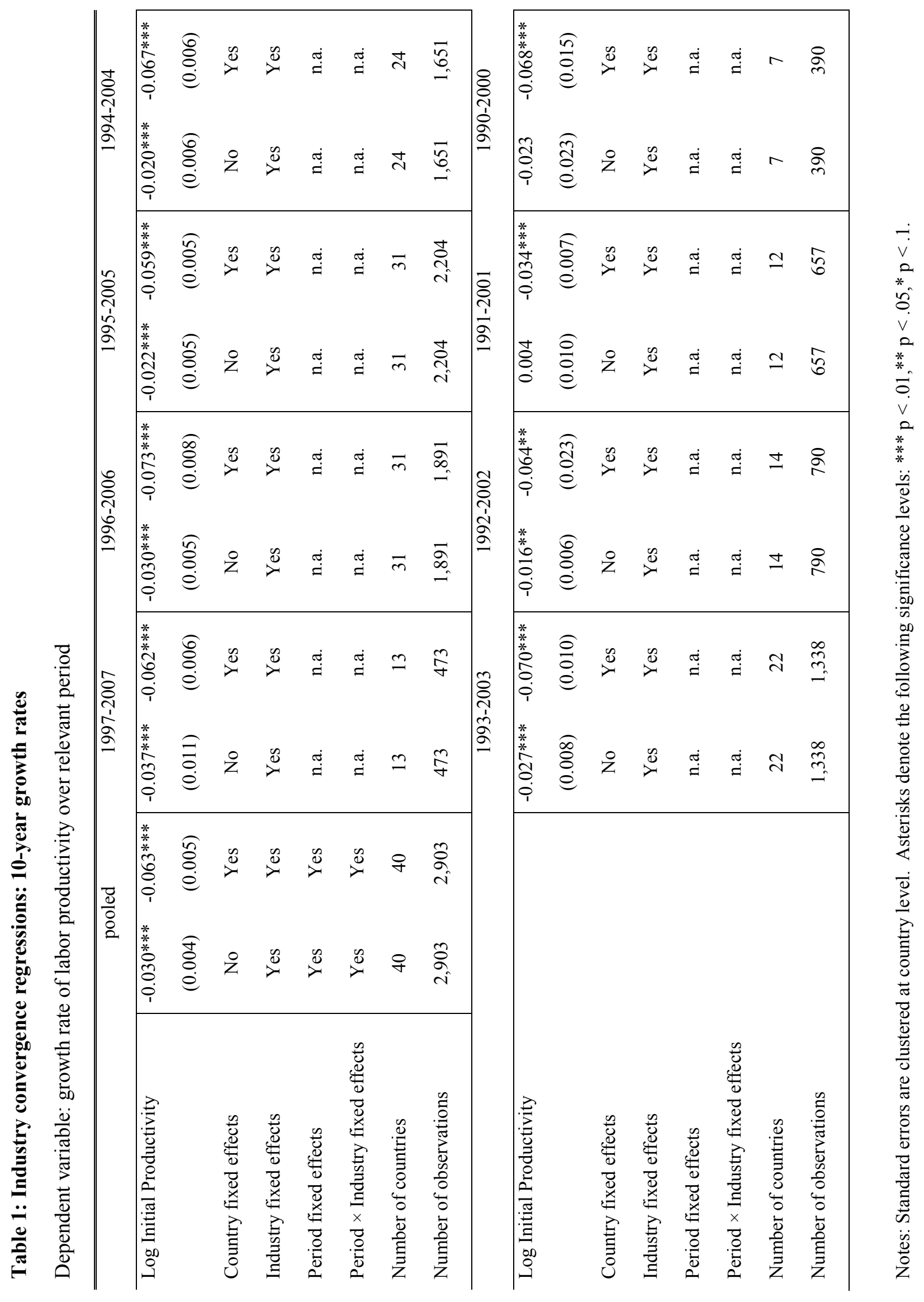




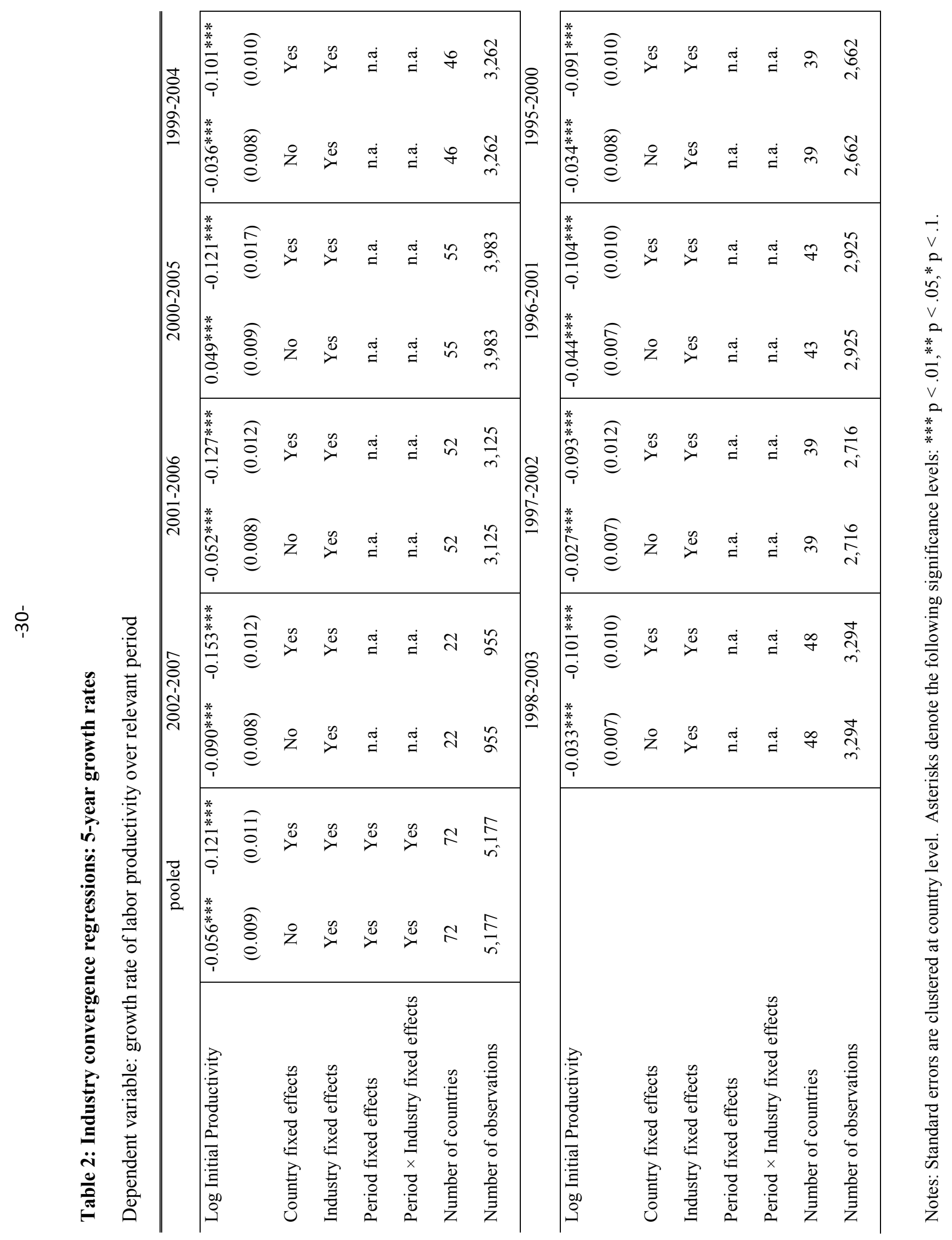




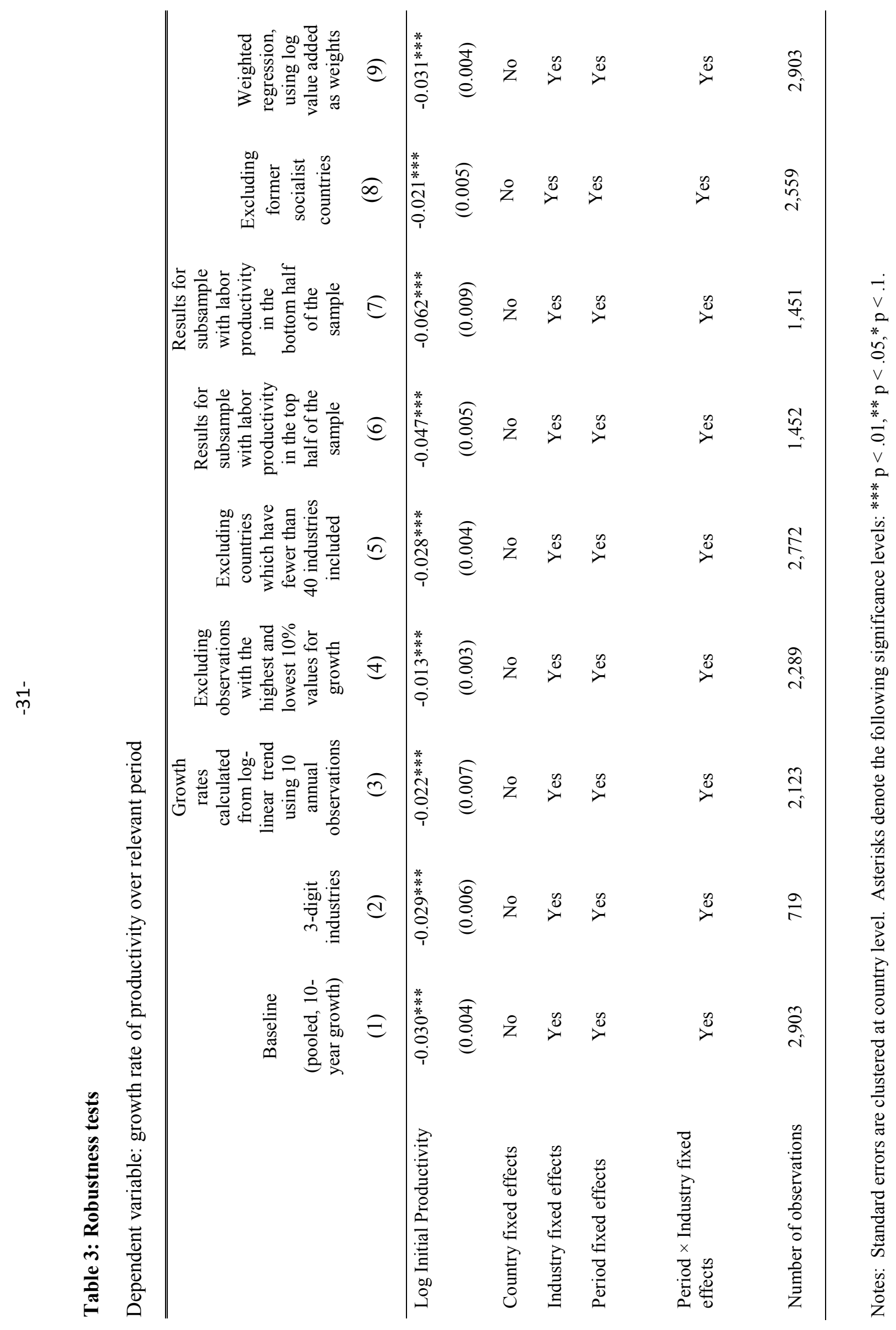




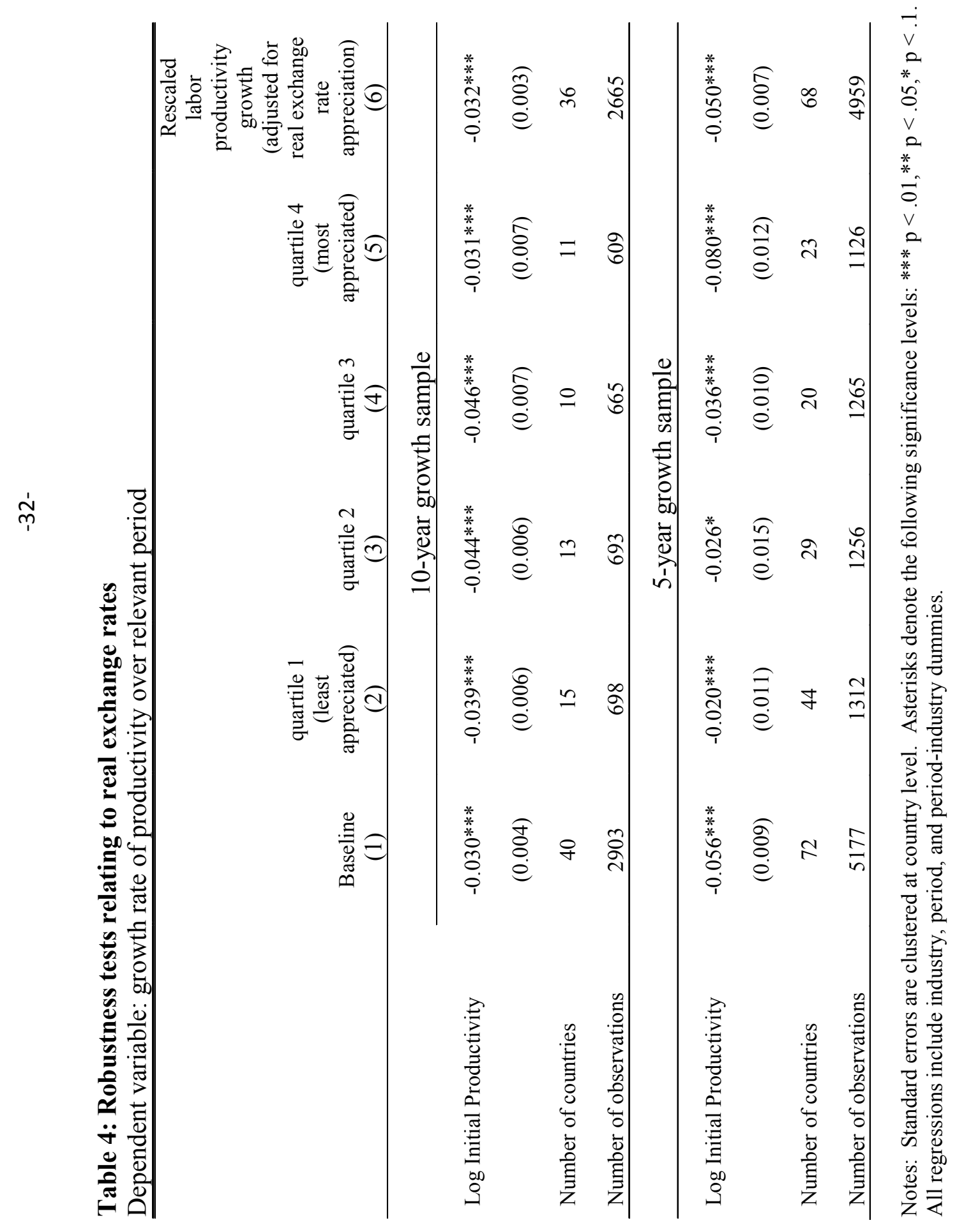




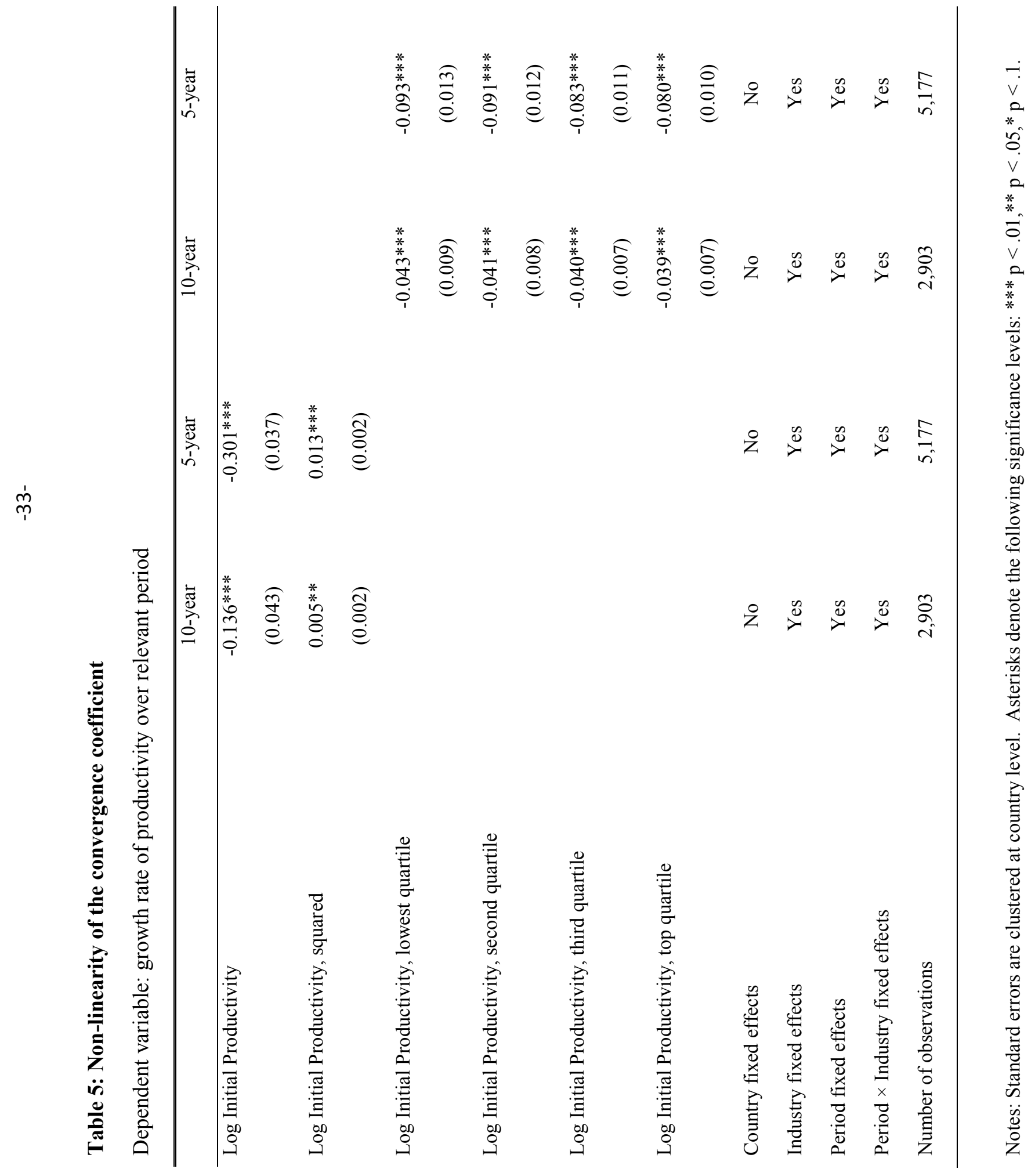




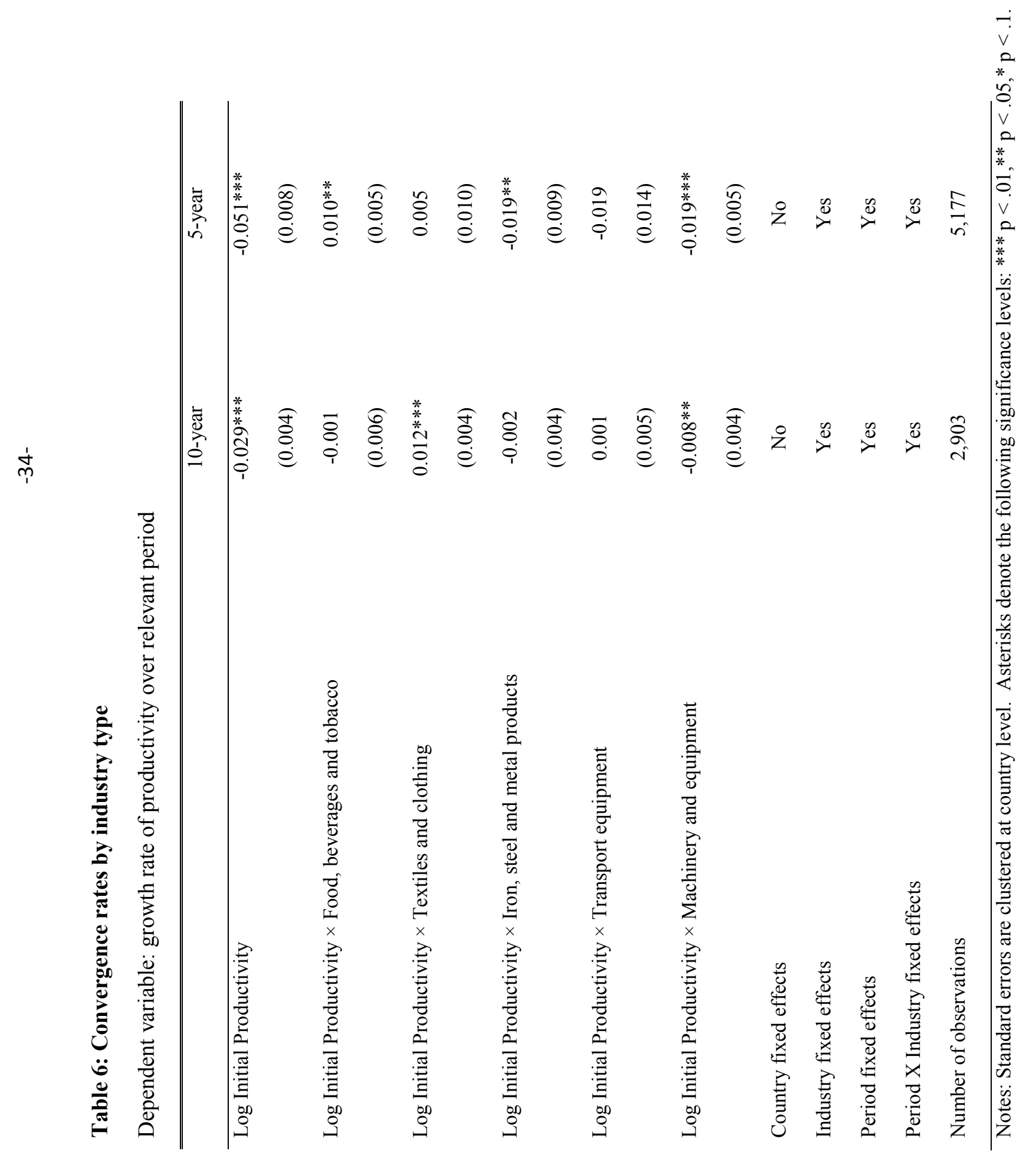




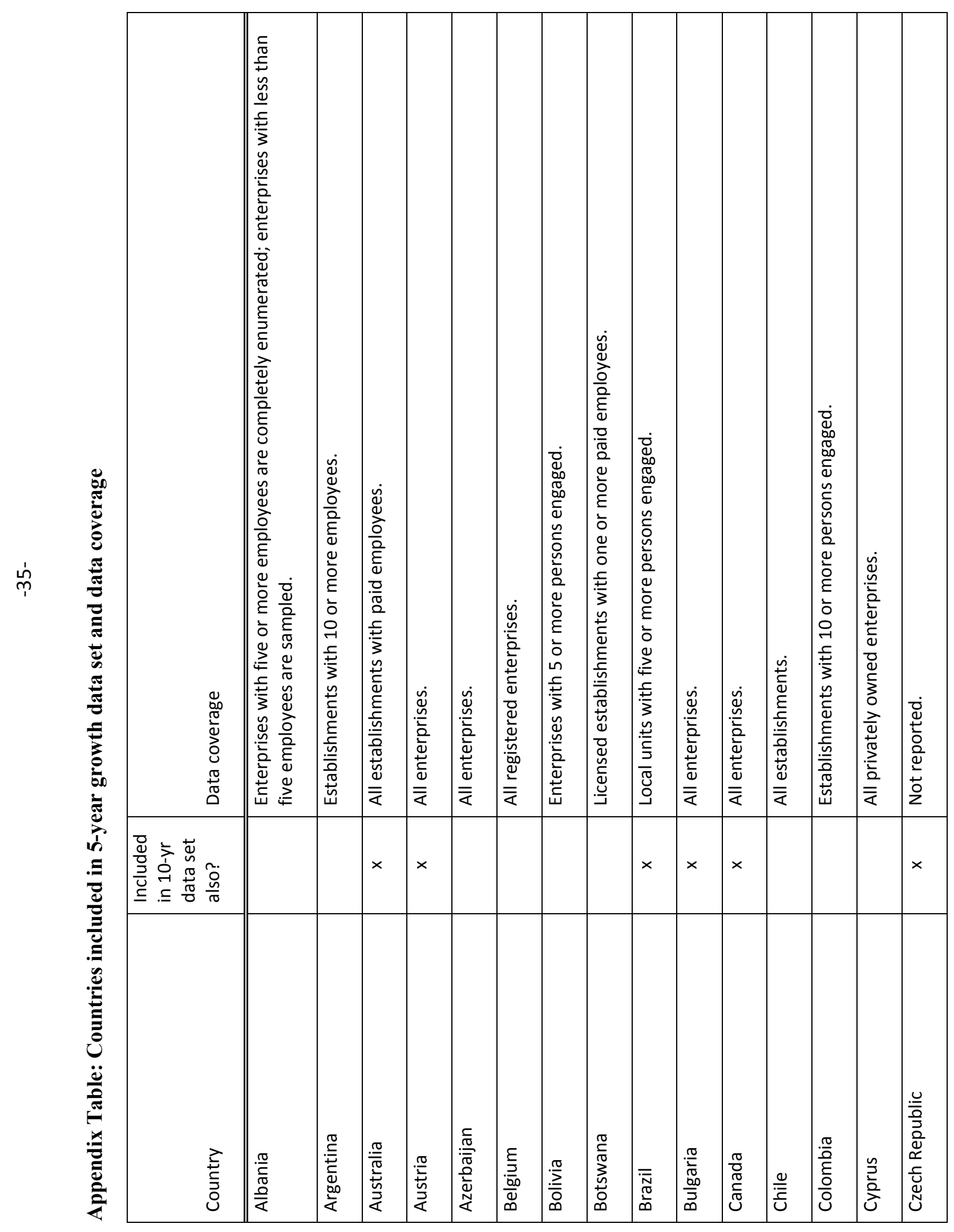




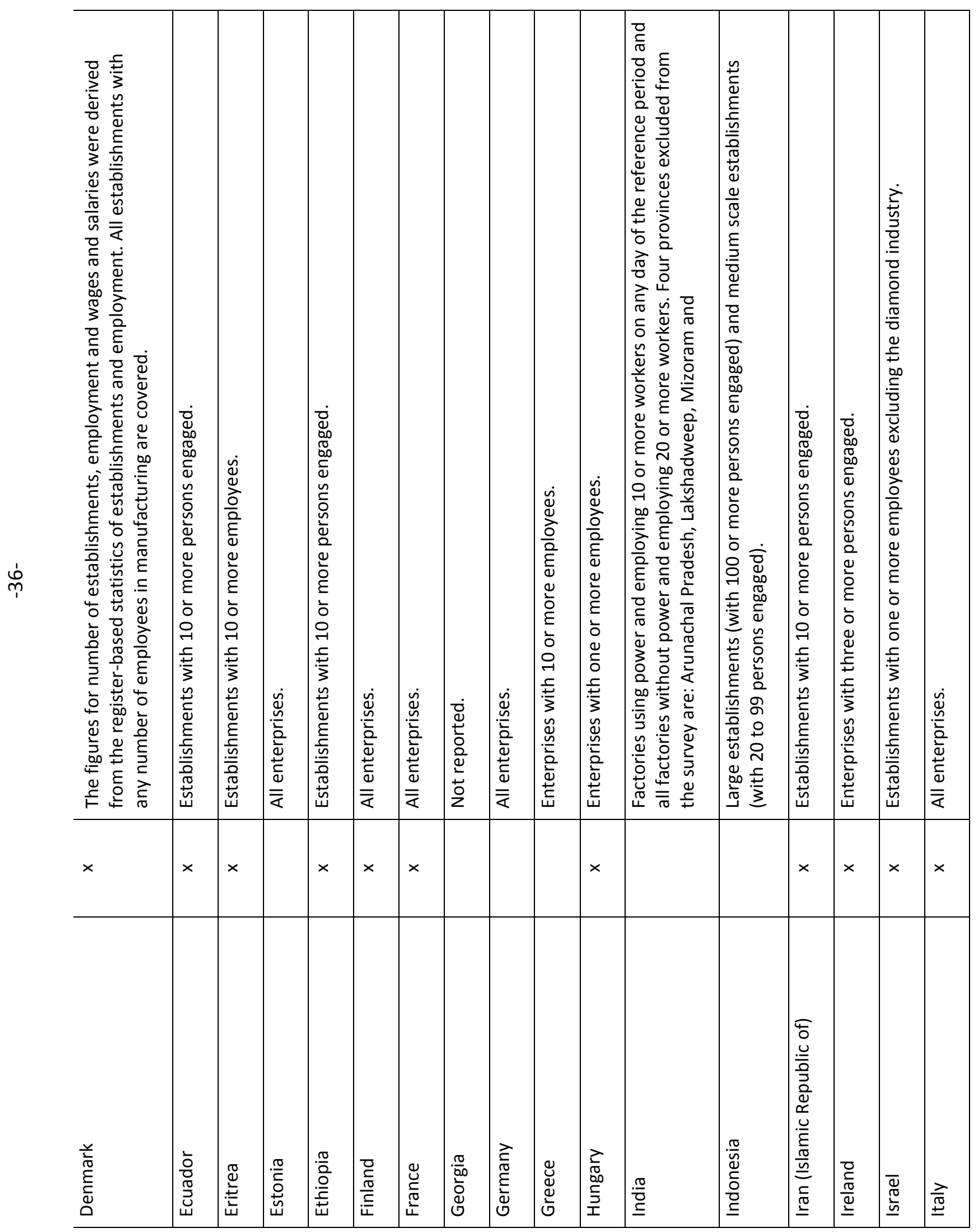




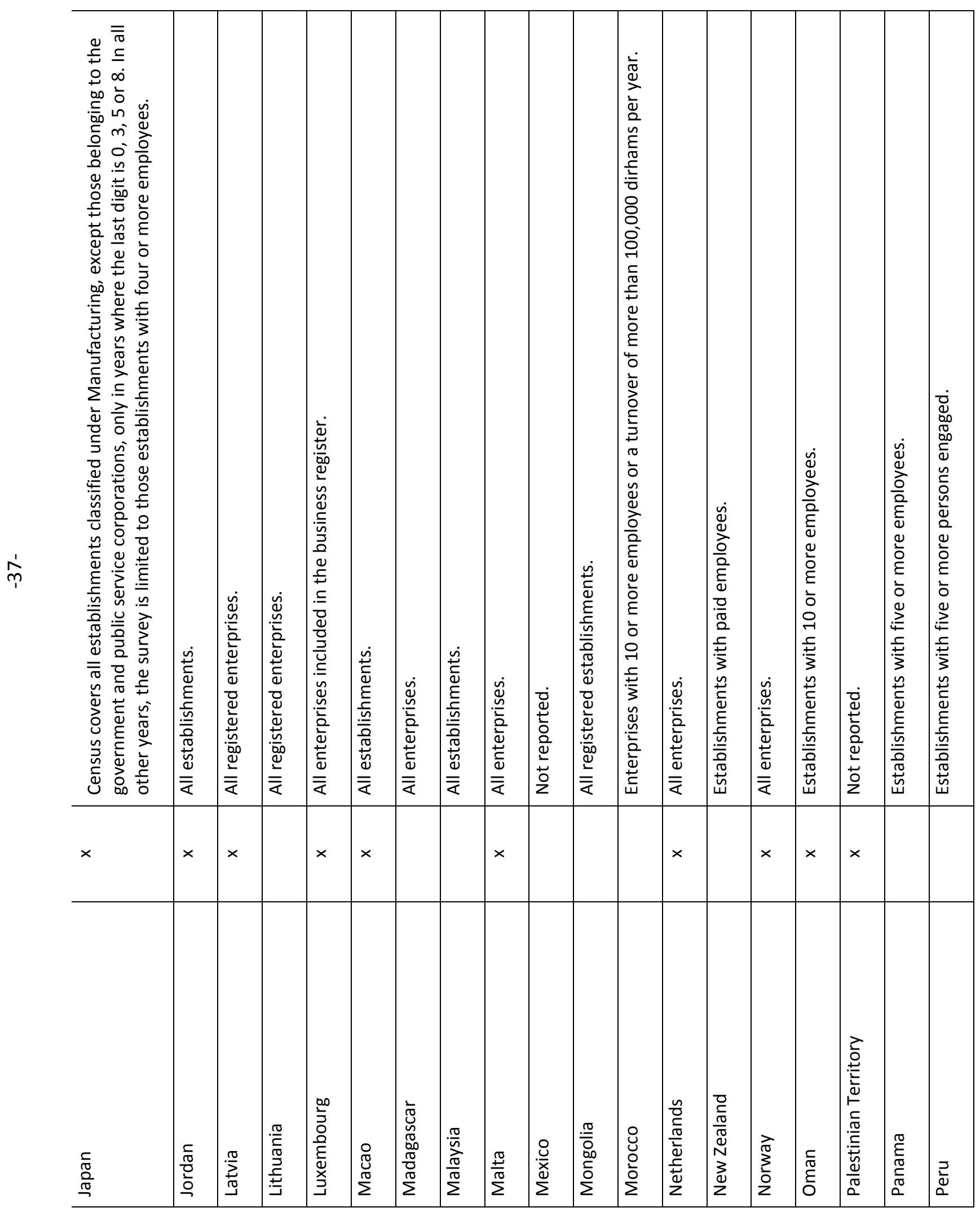




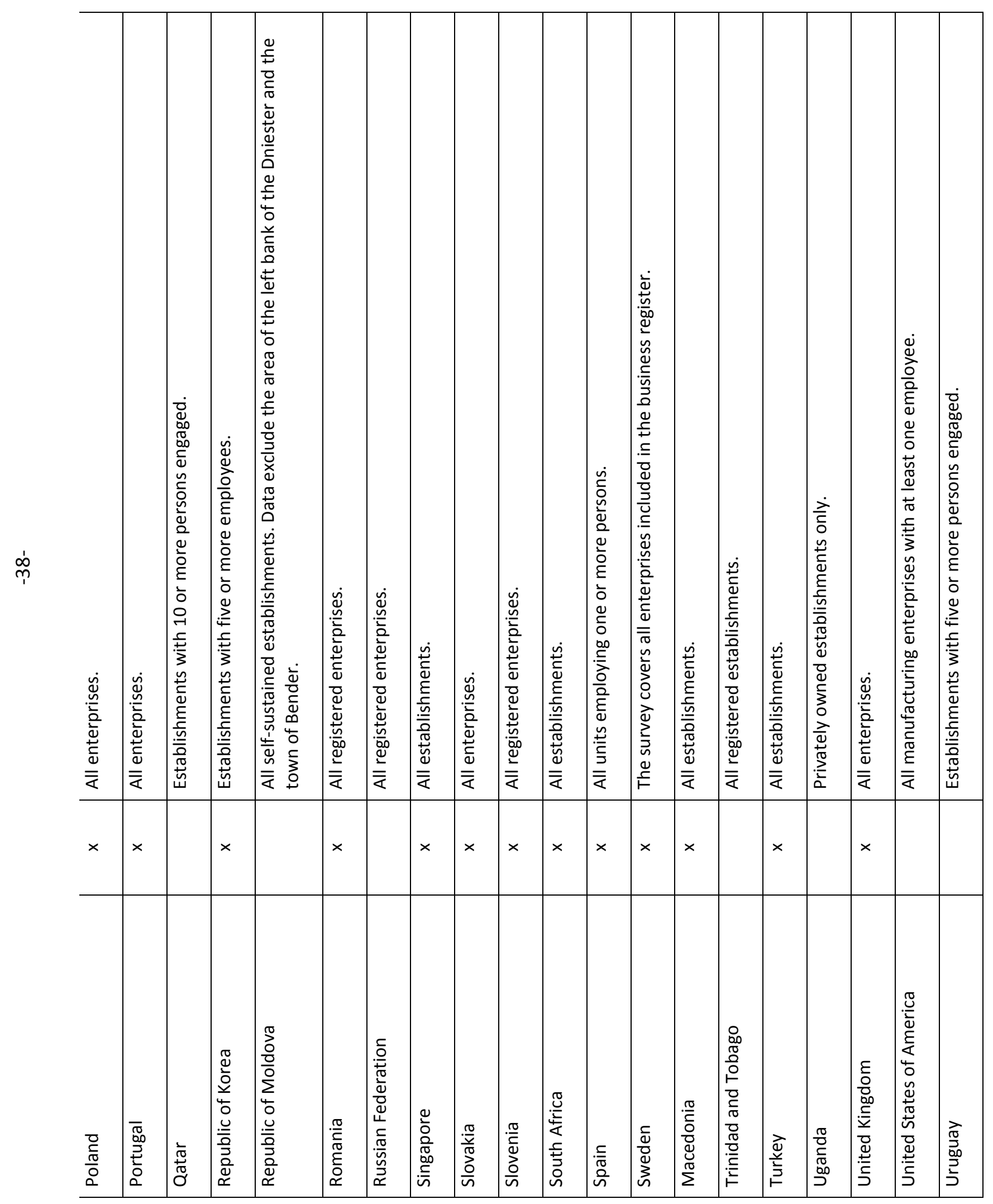




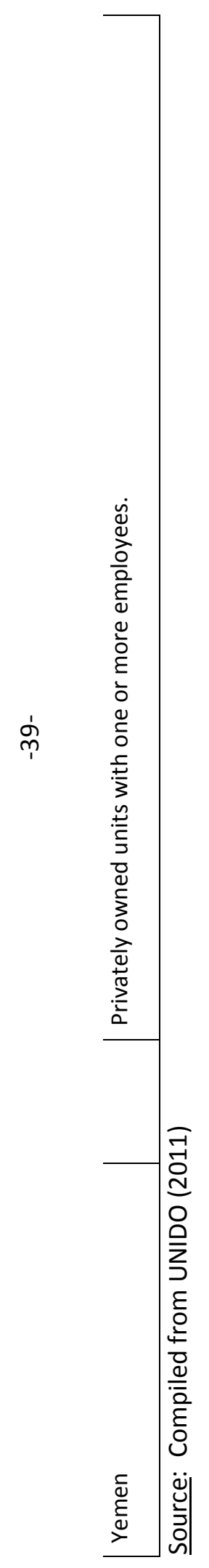

